\title{
TRANSIÇÃO E ARTICULAÇÃO ENTRE EDUCAÇÃO INFANTIL E ENSINO FUNDAMENTAL: ANÁLISE DE DOCUMENTOS OFICIAIS
}

\author{
Mayra Maria de Oliveira Santos \\ Universidade Estadual de Maringá (UEM), Maringá, Paraná, Brasil \\ Maria Angélica Olivo Francisco Lucas \\ Universidade Estadual de Maringá (UEM), Maringá, Paraná, Brasil
}

\begin{abstract}
RESUMO: Este artigo tem como objetivo examinar algumas orientações legais e teórico-metodológicas, veiculadas por documentos oficiais elaborados pelo Ministério da Educação e pelo Conselho Nacional de Educação, acerca da transição e articulação entre a educação infantil e o ensino fundamental. Trata-se de uma pesquisa bibliográfica, com base na Teoria Histórico-Cultural, marco teórico desta pesquisa. Inicialmente, discutimos a relação entre ensino, aprendizagem e desenvolvimento. Em seguida, revisitamos as finalidades da educação infantil e do ensino fundamental defendidas por documentos oficiais e examinamos os conceitos de aprendizagem e desenvolvimento neles presentes. A partir dessa análise, discutimos a transição e a articulação entre as duas etapas de escolarização em questão, apontando a necessidade de reorganização do ensino.
\end{abstract}

PalAVRAS-ChaVE: Transição. Articulação. Educação Infantil. Ensino Fundamental.

\section{INTRODUÇÃO}

As discussões a respeito da transição e articulação entre a educação infantil e o ensino fundamental não são recentes. Na década de 1980, por exemplo, marcada pelo processo de abertura política e democratização da sociedade brasileira, foram frequentes as manifestações em defesa do direito da criança, desde a mais tenra idade, à educação, bem como a busca por uma finalidade pedagógica para as creches e préescolas de então, com vistas a superar as funções de guarda e preparatória que, historicamente, caracterizaram tais instituições (KRAMER, 1987). Naquele contexto, pensar a transição da pré-escola para a $1^{\text {a }}$ série do $1^{\circ} \mathrm{grau}$, conforme denominações do período em destaque, significava tratar uma etapa da educação como preparatória, ou pré-requisito da outra. Também era comum justificar o fracasso escolar com base na ideia de "maturidade", recaindo, na maioria das vezes, todas mazelas do sistema de ensino sobre a criança que não aprendia a ler, escrever e contar e que, por isso, repetia o ano escolar.

Essa contenda começou a ser reanimada a partir da implantação da Lei $\mathrm{n}$. 11.114 (BRASIL, 2005) que modificou a atual LDB (Lei n. 9.394/96) ao alterar a idade de matrícula das crianças no ensino fundamental para a partir dos 6 anos de idade. No entanto, este documento manteve a duração de oito anos para essa etapa da educação. No ano seguinte, foi promulgada a Lei n. 11.274 (BRASIL, 2006) que estabeleceu a ampliação do ensino fundamental, que passou a ter nove anos de duração, com 
matrícula obrigatória a partir dos 6 anos de idade. Tal ampliação corresponde à segunda meta destinada ao ensino fundamental, proposta pela Lei n. 10.172/2001, que regia o Plano Nacional de Educação (PNE) com duração de dez anos a partir de sua publicação em 2001.

Além disso, no ano de 2013, a Lei n. 12.796 (BRASIL, 2013) implantou a educação obrigatória e gratuita dos 4 aos 17 anos de idade, reorganizando a educação básica que ficou assim estruturada:

- educação infantil, para crianças de até 5 anos de idade, sendo creche para aquelas com até 4 anos e pré-escola para as de 4 e 5 anos;

- ensino fundamental, para crianças e adolescentes dos 6 aos 14 anos de idade, básica.

- ensino médio, para adolescentes e jovens, com vistas à conclusão da educação

No transcurso desse processo, vários documentos foram elaborados pelo Ministério da Educação (MEC) e pelo Conselho Nacional de Educação (CNE), contendo dois tipos de orientações: legais e teórico-metodológicas. As primeiras tratam de fundamentos que orientam as escolas brasileiras quanto a organização estrutural, destacando as finalidades da educação infantil e do ensino fundamental. As segundas abordam a concepção de aprendizagem e de desenvolvimento que subjazem os encaminhamentos didáticos. O conhecimento de tais orientações amplia o entendimento sobre a forma como os documentos analisados concebem a transição e a articulação entre as duas primeiras etapas da educação básica.

A despeito da existência de tais orientações e diante da obrigatoriedade da préescola e da escassez de vagas em instituições públicas de educação infantil, muitos municípios transferiram as classes pré-escolares para escolas de ensino fundamental, as quais, em sua maioria, não possuem nem infraestrutura e nem profissionais com formação específica para trabalhar com crianças nessa faixa etária. Desse quadro emergiram dúvidas entre os professores acerca dos limites entre uma e outra etapa de escolarização, alimentando discussões a respeito da transição e da articulação entre ambas. $O$ problema apresentado foi materializado na seguinte pergunta: como os atuais documentos oficiais, elaborados pelo MEC e pelo CNE, abordam a transição e a articulação entre a educação infantil e o ensino fundamental?

Diante desta questão, o objetivo deste trabalho é apresentar as principais orientações legais e teórico-metodológicas veiculadas por documentos oficiais, elaborados pelo MEC e pelo CNE, acerca da transição e articulação entre a educação infantil e os anos iniciais do ensino fundamental.

Além da Constituição Federal e da atual LDB - Lei n. 9.394/96 (BRASIL, 1996), para a consecução de tal objetivo foram analisados documentos elaborados a partir de 2006, marco da ampliação do ensino fundamental para 9 anos de duração, definido como limite temporal deste estudo. São eles:

- Diretrizes Curriculares Nacionais para a Educação Infantil (DCNEI) (BRASIL, 2009a);

- Parecer CNE/CEB n. 20/2009, que revisa as DCNEI, implementadas em 7 de abril de 1999 (BRASIL, 2009b); 
SANTOS, M. M. de O.; LUCAS, M. A. O F.

- Diretrizes Curriculares Nacionais para o Ensino Fundamental de nove anos (DCNEF) (BRASIL, 2010b);

- Parecer CNE/CEB n. 11/2010, que institui as DCNEF (BRASIL, 2010a);

- Diretrizes Curriculares Nacionais para a Educação Básica (BRASIL, 2013);

- Base Nacional Comum Curricular (BNCC) (BRASIL, 2017).

A apresentação da análise deste rol de documentos, a partir do objetivo anteriormente exposto, foi dividida em quatro partes. Na primeira, apresentamos a concepção de aprendizagem e de desenvolvimento, com base na Teoria HistóricoCultural (THC), abordando a apropriação dos conceitos científicos; a periodização do desenvolvimento infantil e as atividades principais, referentes aos períodos pelos quais passa a criança em transição entre a educação infantil e ensino fundamental.

Mediante a complexidade do nosso objeto de estudo, na segunda parte apresentamos algumas orientações legais para a organização do ensino na educação infantil e no ensino fundamental, presentes nos documentos mencionados. Dentre tais orientações, a partir de uma retrospectiva histórica, destacamos as que dizem respeito às finalidades destas duas etapas da educação básica. $\mathrm{Na}$ terceira parte, elencamos as principais orientações teórico-metodológicas destinadas à educação infantil e ao ensino fundamental, presentes nos documentos mencionados, enfatizando concepções de aprendizagem e desenvolvimento por eles defendidas.

Por fim, na última parte, de posse das orientações legais associadas às finalidades destas duas etapas da educação básica e das orientações teóricometodológicas, relacionadas às concepções de aprendizagem e desenvolvimento, discorremos acerca da forma como os documentos analisados abordam a transição e a articulação entre tais etapas, salientando as instruções dirigidas às instituições de ensino e aos professores.

À guisa de conclusão, adiantamos que em nossos estudos a respeito da transição e articulação entre a educação infantil e o ensino fundamental, considerando suas finalidades definidas pelos documentos oficiais, os processos de aprendizagem e desenvolvimento à luz da THC, bem como a periodização do desenvolvimento infantil e o conceito de atividade principal, obtivemos resultados que indicam a necessidade de reorganizar o ensino em ambas etapas da educação básica. Pois, somente integrando as práticas pedagógicas podemos possibilitar às crianças a apropriação de novos conhecimentos e de novas formas de pensar e de agir em sociedade.

\section{ENSINO, APRENDIZAGEM E DESENVOLVIMENTO HUMANO}

Para a THC, aprendizagem e desenvolvimento são processos distintos, havendo entre ambos complexas inter-relações. Ao investigarmos os pressupostos defendidos por Vigotski (2001) a respeito da relação entre tais processos, deparamo-nos com dois conceitos: nível de desenvolvimento real ou atual e zona de desenvolvimento próximo. O primeiro abrange os conhecimentos e as habilidades que a criança já possui, ou seja, o que ela consegue executar sem necessitar de auxílio. O segundo se refere aos conhecimentos e habilidades que a criança passa a dominar a partir da mediação realizada por outros sujeitos mais experientes. Assim, o ensino promove a aprendizagem que gera o desenvolvimento. 
Ao considerar a necessidade do ensino para a aprendizagem e o desenvolvimento da criança, Vigotski (2001) reconhece a existência de um limite tanto inferior quanto superior de instrução, pois, somente estando entre esses limites, a instrução pode colaborar para o desenvolvimento do sujeito. Assim, compreendemos que é necessária a organização de atividades de ensino que considerem a conexão existente entre a aprendizagem e o nível de desenvolvimento da criança. Tendo em vista que, para o autor, o desenvolvimento avança mais lentamente, mas em conexão ao seu processo de aprendizagem.

Esse princípio, exposto por Vigotski $(2001 ; 2006)$, possibilita a compreensão acerca da aprendizagem de conceitos científicos, que não presume o desaparecimento do conceito espontâneo; ao contrário, para que haja internalização do conceito científico, é necessário que a criança tenha antes dominado a sua forma espontânea e que esta atinja certo grau para que então a criança possa aprender o conceito científico.

Em consonância com Sforni (2016), entendemos que o conhecimento científico não independe do conhecimento espontâneo, pois ambos fazem parte do processo de aprendizagem e desenvolvimento da criança, sendo possível, por meio da organização do ensino, proporcionar novas formas de perceber e de organizar o real de maneira abstrata, tornando presente aquilo que está fisicamente ausente para a criança, ao internalizar os conceitos. Assim, a relação entre conhecimento científico e espontâneo confirma o princípio acima exposto: aprendizagem gera desenvolvimento.

Por isso, Leontiev (2006) dedicou-se a estudar o desenvolvimento humano, periodizando-o. Para ele, "as condições históricas concretas exercem influência tanto sobre o conteúdo concreto de um estágio individual do desenvolvimento, como sobre o curso total do processo de desenvolvimento psíquico como um todo" (LEONTIEV, 2006, p. 65). Ou seja, o desenvolvimento humano segue caminhos diferentes em cada forma de organização social e em momentos diferentes da história, gerando, consequentemente, fases ou períodos também distintos.

Ao nos fundamentarmos em estudos realizados por Elkonin, Pasqualini e Eidt (2016), afirmamos que o desenvolvimento infantil pode ser dividido em três épocas: primeira infância, infância e adolescência. Cada época, por sua vez, é composta por dois períodos: a primeira infância é composta pelo primeiro ano; a infância pela idade préescolar e idade escolar; e a adolescência pela adolescência inicial e adolescência. Cada período em si, é composto por uma atividade principal, que é responsável por formar e reorganizar os processos psíquicos, gerando novos tipos de atividade que, por sua vez, novamente, provocam mudanças no psiquismo, possibilitando a transição para um novo período de desenvolvimento.

Em consideração aos períodos de desenvolvimento pelos quais as crianças em idade de transição da educação infantil para o ensino fundamental percorrem, de acordo com as autoras mencionadas, no período pré-escolar a atividade principal é o jogo de papéis, e na idade escolar, o estudo. Desse modo, tais etapas da educação básica corresponderiam à transição de um período de desenvolvimento psíquico a outro, os quais determinam que a atividade dominante, até então o jogo de papéis, passará a ser a atividade de estudo, momento no qual a criança, além de representar brincando, inicia, de modo sistematizado, a aprendizagem dos conhecimentos científicos. 
SANTOS, M. M. de O.; LUCAS, M. A. O F.

No entanto, a transição de uma atividade dominante a outra não coincide com a transição de uma etapa da educação a outra, haja vista que, atualmente, as crianças iniciam tanto a educação infantil quanto o ensino fundamental em tenra idade. Dessa maneira, torna-se ainda mais justificável a necessidade de organização do ensino para que a atividade principal brincar não se transforme imediatamente na outra atividade principal estudar, uma vez que a criança, ao iniciar o ensino fundamental, ainda não gestou por completo o desenvolvimento psíquico referente à atividade de estudo.

Apesar de plenos em avanços e recuos, há que se considerar o aspecto contínuo dos processos de aprendizagem e desenvolvimento, assim como dos períodos de desenvolvimento pelos quais passam os alunos, incluindo a atividade principal específica de cada período, como condição para a organização de um ensino sistematizado e intencional, tanto na educação infantil como no ensino fundamental. Nessa direção, torna-se indispensável, ao tratarmos da transição e articulação entre estas duas etapas da educação básica, analisarmos as suas finalidades definidas pelos documentos oficiais, elaborados pelo MEC e pelo CNE, que orientam as ações dos profissionais da educação das escolas brasileiras.

\section{PRINCIPAIS ORIENTAÇÕES LEGAIS: REVISITANDO AS FINALIDADES DA EDUCAÇÃO INFANTIL E DO} ENSINO FUNDAMENTAL

Fundamentadas na Constituição Federal (BRASIL, 1988), na LDB atual (BRASIL, 1996) e nas demais leis que regem a educação básica no país, atentamo-nos às Diretrizes Curriculares Nacionais para a Educação Básica (BRASIL, 2013), as quais, devido à reorganização da educação brasileira anteriormente exposta, foram atualizadas mediante a realização de estudos, de debates e de audiências públicas, todos organizados pela Câmara da Educação Básica do Conselho Nacional de Educação (CEB/CNE). Também participaram da sua reelaboração entidades representativas de dirigentes dos estados, dos municípios, professores e funcionários da área da educação, instituições de formação de professores etc.

As Diretrizes Curriculares Nacionais para a Educação Básica são um conjunto de princípios, de fundamentos teórico-metodológicos e de procedimentos didáticos que orientam as escolas brasileiras "[...] na organização, articulação, desenvolvimento e avaliação de suas propostas pedagógicas" (BRASIL, 2013, p. 82). São compostas por vários documentos, dentre os quais destacamos as DCNEI (BRASIL, 2009a) e as DCNEF (BRASIL, 2010b). Esse conjunto de documentos definem, juntamente aos seus respectivos Pareceres no CNE - Parecer CNE/CEB n. 20/2009 (BRASIL, 2009b) e Parecer CNE/CEB n. 11/2010 (BRASIL, 2010a, p. 12), acompanhados pela atual LDB, as finalidades da educação infantil e do ensino fundamental.

A educação infantil, primeira etapa da educação básica, de acordo com o Art. 29 da LDB, possui a seguinte finalidade: desenvolver integralmente a criança de 0 a 5 anos de idade em seus aspectos físico, afetivo, intelectual, linguístico e social, devendo completar as ações da família e da comunidade.

Nessa direção, as instituições de educação infantil, conforme o Parecer CNE/CEB n. 20/2009 (BRASIL, 2009b), devem entender o cuidado como algo indissociável do processo educativo, além de assegurar às crianças a educação em sua integralidade. Assim: 
As práticas pedagógicas devem ocorrer de modo a não fragmentar a criança nas suas possibilidades de viver experiências, na sua compreensão do mundo feita pela totalidade de seus sentidos, no conhecimento que constrói na relação intrínseca entre razão e emoção, expressão corporal e verbal, experimentação prática e elaboração conceitual (BRASIL, 2009b, p. 9).

Desse modo, o documento retrata que o cuidar, na educação infantil, não possui o objetivo de simplesmente garantir a integridade física da criança, mas de respeitar o seu direito à aprendizagem e ao desenvolvimento, por meio de experiências mediadas pelos professores, os quais, de maneira intencional, planejam e organizam as suas práticas pedagógicas.

No percurso da educação infantil, a criança realiza importantes aquisições, como "[...] a marcha, a fala, o controle esfincteriano, a formação da imaginação e da capacidade de fazer de conta e de representar usando diferentes linguagens" (BRASIL, 2009b, p. 7). No entanto, segundo o documento, embora a dimensão orgânica das crianças esteja presente nessas aquisições, para que elas possam "[...] discriminar cores, memorizar poemas, representar uma paisagem através de um desenho", por exemplo, não é necessário o seu amadurecimento biológico, porque tais aquisições são "[...] histórica e culturalmente produzidas nas relações que estabelecem com o mundo material e social mediadas por parceiros mais experientes" (BRASIL, 2009b, p. 7).

Nesse contexto, há a defesa de que

[...] a motricidade, a linguagem, o pensamento, a afetividade e a sociabilidade são aspectos integrados e se desenvolvem a partir das interações que, desde o nascimento, a criança estabelece com diferentes parceiros, a depender da maneira como sua capacidade para construir conhecimento é possibilitada e trabalhada nas situações em que ela participa. Isso por que, na realização de tarefas diversas, na companhia de adultos e de outras crianças, no confronto dos gestos, das falas, enfim, das ações desses parceiros, cada criança modifica sua forma de agir, sentir e pensar (BRASIL, 2009b, p. 7).

Para tanto, torna-se necessário que os professores se atentem à intencionalidade de suas ações pedagógicas, levando em consideração os itens anteriormente citados e, principalmente, a importante interação entre as crianças, os professores e os demais sujeitos sociais. Com todos esses aspectos articulados e planejados, entendemos que é possível caminhar rumo ao atendimento das finalidades da educação infantil, conforme preconiza o Parecer CNE/CEB n. 20/2009 (BRASIL, 2009b).

Em relação ao ensino fundamental, a atual LDB, em seu Art. $32^{\circ}$, institui como objetivos específicos dessa etapa da educação a formação básica do cidadão mediante:

I - o desenvolvimento da capacidade de aprender, tendo como meios básicos o pleno domínio da leitura, da escrita e do cálculo; 
SANTOS, M. M. de O.; LUCAS, M. A. O F.

\begin{abstract}
II - a compreensão do ambiente natural e social, do sistema político, da tecnologia, das artes e dos valores em que se fundamenta a sociedade;

III - o desenvolvimento da capacidade de aprendizagem, tendo em vista a aquisição de conhecimentos e habilidades e a formação de atitudes e valores;

IV - o fortalecimento dos vínculos de família, dos laços de solidariedade humana e de tolerância recíproca em que se assenta a vida social (BRASIL, 1996, p. 23).
\end{abstract}

Assim dispostas, as principais finalidades do ensino fundamental regidas pelo documento mencionado devem ser consideradas pelos demais documentos que orientam a educação, as escolas e os professores.

De acordo com o Parecer CNE/CEB n. 11/2010, a escola é a principal e, em muitos casos, a única forma de acesso ao conhecimento sistematizado para a maior parte da população brasileira. Essa situação transfere ao ensino fundamental uma parcela ainda maior de responsabilidade em sua função de garantir a todos "[...] a aprendizagem dos conteúdos curriculares capazes de fornecer os instrumentos básicos para a plena inserção na vida social, econômica e cultural do país" (BRASIL, 2010a, p. 12).

Dessa forma, as DCNEF (BRASIL, 2010b) afirmam que a escola, ao desempenhar sua função educativa, deve acolher os educandos de diferentes grupos sociais, atendendo às suas características cognitivas e culturais por meio da construção e da utilização de métodos, de estratégias e de recursos que possibilitem que os alunos conheçam o ambiente. Assim, acolher torna-se uma importante finalidade do ensino fundamental, como exposto a seguir:

Acolher significa, também, garantir as aprendizagens propostas no currículo para que o aluno desenvolva interesses e sensibilidades que lhe permitam usufruir dos bens culturais disponíveis na comunidade, na sua cidade ou na sociedade em geral, e que the possibilitem, ainda, sentir-se como produtor valorizado desses bens. Ao lado disso, a escola é, por excelência, o lugar em que é possível ensinar e cultivar as regras do espaço público que conduzem ao convívio democrático com as diferenças, orientado pelo respeito mútuo e pelo diálogo. É nesse espaço que os alunos têm condições de exercitar a crítica e de aprender a assumir responsabilidades em relação ao que é de todos (BRASIL, 2010b, p. 12).

Os documentos analisados definem que a principal finalidade do ensino fundamental é a formação dos alunos como cidadãos e participantes ativos da sociedade. Demonstram ainda a importância das relações entre escola e família, escola e comunidade, professores e alunos e, por fim, do acolhimento das crianças com sua interação e participação no ambiente escolar e na sociedade.

Dessa forma, entendemos que a efetivação das finalidades, tanto da educação infantil quanto do ensino fundamental, está atrelada às orientações teóricometodológicas que dizem respeito à concepção de aprendizagem e de desenvolvimento defendida pelos documentos estudados, sobre as quais trataremos a seguir. 
PRINCIPAIS ORIENTAÇÕES TEÓRICO-METODOLÓGICAS: REVISITANDO OS CONCEITOS DE APRENDIZAGEM E DESENVOLVIMENTO

De acordo com as DCNEI (BRASIL, 2009a), são definidos como eixos estruturantes da educação infantil: as interações e a brincadeira, pois possibilitam às crianças a apropriação de conhecimento por meio da relação com os adultos e com as demais crianças. Nesse momento, como consequência de suas ações, temos como foco principal o processo de socialização, condição para a aprendizagem e o desenvolvimento infantil.

Também nesse sentido, a BNCC (BRASIL, 2017) busca assegurar condições para que as crianças aprendam em situações nas quais possam desempenhar um papel ativo em ambientes que as convidem a vivenciar desafios e a se sentirem provocadas a resolvê-los, assim como a construir significados sobre si, sobre os outros e sobre os mundos social e natural. Para tanto, o referido documento apresenta seis direitos de aprendizagem e de desenvolvimento: conviver, brincar, participar, explorar, expressar e conhecer-se.

Com o intuito de atender a esses direitos, a organização curricular da educação infantil foi estruturada em cinco campos de experiências que definem seus objetivos de aprendizagem e de desenvolvimento. No Quadro 1 destacamos os campos de experiências e sintetizamos os conteúdos abordados, respectivamente:

\begin{tabular}{|c|c|}
\hline $\begin{array}{l}\text { Campo de } \\
\text { experiências }\end{array}$ & Conteúdos abordados \\
\hline $\begin{array}{l}\text { O eu, o outro } \\
\text { e o nós }\end{array}$ & $\begin{array}{l}\text { Interagir com os pares e com os adultos, relações necessárias à formação } \\
\text { de identidade, aos modos de agir e de pensar. }\end{array}$ \\
\hline $\begin{array}{l}\text { Corpo, } \\
\text { gestos e } \\
\text { movimentos }\end{array}$ & $\begin{array}{l}\text { Explorar e vivenciar movimentos, gestos, olhares, sons e mímicas com o } \\
\text { corpo, a fim de descobrir o espaço a sua volta e o espaço de ocupação } \\
\text { (rastejar, engatinhar, caminhar utilizando apoio, correr, escorregar, escalar, } \\
\text { saltar, dar cambalhotas, equilibrar-se, entre outros). }\end{array}$ \\
\hline $\begin{array}{l}\text { Traços, } \\
\text { sons, cores } \\
\text { e formas }\end{array}$ & $\begin{array}{l}\text { Favorecer o desenvolvimento da sensibilidade, da criatividade e da } \\
\text { expressão pessoal por meio de experiências como as artes visuais (pintura, } \\
\text { modelagem, colagem, fotografia), a música, o teatro, a dança etc. }\end{array}$ \\
\hline $\begin{array}{l}\text { Escuta, fala, } \\
\text { pensamento e } \\
\text { imaginação }\end{array}$ & $\begin{array}{l}\text { Explorar textos diversos (literatura infantil, contos, fábulas, poemas etc.) } \\
\text { para conhecer as funções da escrita; desenvolver o gosto pela leitura e a } \\
\text { familiaridade com diferentes gêneros literários; diferenciar ilustrações e } \\
\text { escrita; aprender a direção da escrita e a manipular corretamente um livro. }\end{array}$ \\
\hline $\begin{array}{l}\text { Espaços, tempos, } \\
\text { quantidades, } \\
\text { relações e } \\
\text { transformações }\end{array}$ & $\begin{array}{l}\text { Observar e manipular objetos, investigar e explorar o espaço a sua volta, } \\
\text { levantar hipóteses e consultar fontes de informação para buscar respostas } \\
\text { às perguntas e às curiosidades apontadas, oportunizando, dessa forma, a } \\
\text { ampliação de conhecimentos sobre o seu mundo físico e sociocultural. }\end{array}$ \\
\hline
\end{tabular}
Fonte: Elaborado pela autora com base na BNCC (BRASIL, 2017).

É possível compreender que as aprendizagens na educação infantil, de acordo com a BNCC (BRASIL, 2017), englobam tanto os comportamentos, as habilidades e os conhecimentos quanto as vivências capazes de promover a aprendizagem e o 
SANTOS, M. M. de O.; LUCAS, M. A. O F.

desenvolvimento. Para tanto, é necessário recorrer aos eixos estruturantes, pautados nas interações e nas brincadeiras, que têm como embasamento as DCNEl e os campos de experiência apresentados.

Diante disso, cabe ainda ressaltarmos que, conforme as DCNEI (BRASIL, 2009a), as experiências que promovem a aprendizagem e que têm como resultado o desenvolvimento das crianças devem ser regulares e, ao mesmo tempo, imprevisíveis, surpreendentes e abertas a novas descobertas. Pois, como se destinam à criação e à comunicação por meio de formas variadas de expressão, pode se utilizar imagens, músicas, teatro, dança e movimentos etc.

No ensino fundamental, em consonância com as DCNEF (BRASIL, 2010b, p. 9), as crianças interagem mais em espaços públicos, principalmente na escola. Sendo assim, é nesta etapa da educação básica em que se "[...] deve intensificar a aprendizagem das normas da conduta social, com ênfase no desenvolvimento de habilidades que facilitem o processo de ensino e aprendizagem".

Ao longo dos anos iniciais do ensino fundamental, conforme a BNCC (BRASIL, 2017, p. 59),

[...] a progressão do conhecimento ocorre pela consolidação das aprendizagens anteriores e pela ampliação das práticas de linguagem e da experiência estética e intercultural das crianças, considerando tanto seus interesses e suas expectativas quanto o que ainda precisam aprender.

Nessa direção, conforme o Parecer n. 11/2010 - (BRASIL, 2010a), o ingresso de crianças com 6 anos de idade no ensino fundamental objetiva garantir-lhes aprendizagem e desenvolvimento integral, considerando a grande diversidade social, cultural e individual dos alunos, os quais necessitam de espaços apropriados e de tempos diferenciados de aprendizagem. Por isso, o referido documento destaca a importância e a necessidade de se resgatar o caráter lúdico da aprendizagem, que se faz presente na educação infantil, também com crianças de 6 a 10 anos de idade, evitando um ensino repetitivo por meio de aulas mais prazerosas e desafiadoras, em que haja participação ativa dos alunos (BRASIL, 2010a). O documento ainda destaca que a escola deve adotar formas de trabalho que

\footnotetext{
[...] proporcionem maior mobilidade às crianças na sala de aula, explorar com elas mais intensamente as diversas linguagens artísticas, a começar pela literatura, utilizar mais materiais que proporcionem aos alunos oportunidade de raciocinar manuseandoos, explorando as suas características e propriedades, ao mesmo tempo em que passa a sistematizar mais os conhecimentos escolares (BRASIL, 2010a, p. 21).
}

Dessa forma, compreendemos que a aprendizagem e o desenvolvimento nos anos iniciais do ensino fundamental devem ser assegurados por meio de atividades intencionalmente organizadas, visando a maior interação e mobilidade entre as crianças a fim de que possam absorver a essência lúdica da educação infantil. Contudo, sempre buscando o equilíbrio com a abordagem de conhecimentos sistematizados e necessários a essa etapa da educação básica. 
Nesse sentido, entendemos que os processos de aprendizagem e desenvolvimento, tanto no que se refere à educação infantil, quanto ao ensino fundamental, encontram-se intimamente ligados. Considerando que a segunda etapa da educação básica consiste em consolidar as aprendizagens e ampliar as experiências vivenciadas pelas crianças na etapa anterior, as orientações teórico-metodológicas aqui apresentadas tornam-se indispensáveis para pensar a transição e a articulação entre as duas etapas da educação, sobre a qual trataremos a seguir.

\section{TRANSIÇÃO E ARTICULAÇÃO ENTRE EDUCAÇÃO INFANTIL E ENSINO FUNDAMENTAL}

Em sua estrutura, a BNCC (BRASIL, 2017) apresenta uma breve subseção destinada à transição da educação infantil para o ensino fundamental, pautando-se na síntese das aprendizagens do campo de experiências da educação infantil. Enfatiza a necessidade de atenção a esse momento de transição, contemplando a importância do equilíbrio entre as mudanças a serem realizadas, de maneira a garantir "[...] integração e continuidade dos processos de aprendizagens das crianças, respeitando suas singularidades e as diferentes relações que elas estabelecem com os conhecimentos, assim como a natureza das mediações de cada etapa" (BRASIL, 2017, p. 53).

Nessa direção, o documento ressalta ser necessária a formulação de estratégias ligadas ao acolhimento e à adaptação, tanto para alunos quanto para professores, para que, de fato, a nova etapa de ensino seja construída com base no que a criança sabe e é capaz de fazer, dando continuidade a seu percurso educativo e escolar. Para tanto, o uso de relatórios, portfólios, registros das crianças que demonstrem o processo de aprendizagem vivenciado e que contribuam para a compreensão da história escolar de cada estudante, como também de conversas, visitas, trocas de materiais entre professores das duas etapas de ensino são importantes aliados para "[...] facilitar a inserção das crianças nessa nova etapa da vida escolar" (BRASIL, 2017, p. 53).

Assim, quanto ao processo de desenvolvimento da criança, a BNCC (BRASIL, 2017) sintetiza as aprendizagens esperadas em cada campo de experiência como "[...] elemento balizador e indicativo de objetivos a serem explorados" na educação infantil que deverão ser ampliados e aprofundados no ensino fundamental (BRASIL, 2017, p. 53).

Quase uma década antes, as DCNEI (BRASIL, 2009a) afirmavam que as instituições de educação infantil deveriam garantir a continuidade do processo de aprendizagem, criando, para tanto, estratégias adequadas aos diversos momentos de transição vivenciados pela criança, seja a transição de casa para a creche/pré-escola, da educação infantil para o ensino fundamental, entre outras. Em relação à continuidade do processo de aprendizagem e desenvolvimento, o referido documento retrata que:

Na transição para o Ensino Fundamental a proposta pedagógica deve prever formas para garantir a continuidade no processo de aprendizagem e desenvolvimento das crianças, respeitando as especificidades etárias, sem antecipação de conteúdos que serão trabalhados no Ensino Fundamental (BRASIL, 2009a, p. 29). 
SANTOS, M. M. de O.; LUCAS, M. A. O F.

As DCNEF (BRASIL, 2010b) ressaltam que o ensino fundamental se depara com o desafio de se articular às demais etapas de ensino, sendo necessário que essa etapa da educação básica contemple, no caso da transição estudada nesta pesquisa, algumas das práticas que constituem a educação infantil para que seja possível superar barreiras que possam dificultar o percurso escolar dos alunos. O documento mencionado assim expõe:

Art. 29 A necessidade de assegurar aos alunos um percurso contínuo de aprendizagens torna imperativa a articulação de todas as etapas da educação, especialmente do Ensino Fundamental com a Educação Infantil, dos anos iniciais e dos anos finais no interior do Ensino Fundamental, bem como do Ensino Fundamental com o Ensino Médio, garantindo a qualidade da Educação Básica.

$\S 1^{\circ} \mathrm{O}$ reconhecimento do que os alunos já aprenderam antes da sua entrada no Ensino Fundamental e a recuperação do caráter lúdico do ensino contribuirão para melhor qualificar a ação pedagógica junto às crianças, sobretudo nos anos iniciais dessa etapa da escolarização (BRASIL, 2010b, p. 8).

Por conseguinte, ao analisarmos a BNCC (BRASIL, 2017) no que diz respeito à transição e à articulação entre as etapas da educação básica já mencionadas, verificamos apontamentos voltados à importância de nos anos iniciais buscarem-se situações lúdicas de aprendizagem, articulando as experiências vivenciadas pelas crianças na educação infantil:

Tal articulação precisa prever tanto a progressiva sistematização dessas experiências quanto o desenvolvimento, pelos alunos, de novas formas de relação com o mundo, novas possibilidades de ler e formular hipóteses sobre os fenômenos, de testá-las, de refutá-las, de elaborar conclusões, em uma atitude ativa na construção de conhecimentos (BRASIL, 2017, p. 57).

De acordo com o documento, nesse período da vida, a criança vivencia importantes mudanças, principalmente em seu desenvolvimento, as quais transformam suas relações consigo mesmas, com as demais pessoas de seu convívio e com o mundo.

Desse modo, a BNCC (2017) retrata a necessária previsão a ser realizada pelas instituições de educação e por seus professores que devem organizar o ensino de forma a promover a aprendizagem e o desenvolvimento de seus alunos, mediante a manifestação de seus interesses, de suas vivências, de modo a proporcionar a ampliação e a mobilização de suas operações cognitivas, possibilitando que eles possam "aprender o mundo, expressar-se sobre ele e nele atuar" (BRASIL, 2017, p. 58).

\section{À GUISA DE CONCLUSÃO}

A análise dos documentos oficiais aqui arrolados evidencia que a organização da educação brasileira passou por muitas modificações nas últimas décadas, o que exigiu dos estados, municípios, escolas e dos profissionais da educação, diversas 
adaptações, desde as relacionadas à estrutura física das instituições, até a reorganização do ensino.

Esse contexto de mudanças reacendeu as discussões acerca da transição e articulação entre a educação infantil e o ensino fundamental, motivando o estudo apresentado neste artigo, ao longo do qual acolhemos os ensinamentos da THC sobre o processo de aprendizagem e desenvolvimento humano. Destacamos, dentre os principais ensinamentos desse referencial teórico, a apropriação de conceitos espontâneos e científicos, como também a periodização do desenvolvimento infantil. Entendemos que a periodização, elaborada por Leontiev, e as atividades principais, expressas por Elkonin, não coincidem com a ideia de transição e articulação presente nos documentos examinados, visto que, atualmente, as crianças, ainda em idade muito precoce, transitam de uma etapa a outra da educação básica e passam do brincar à atividade de estudo de forma abrupta. Modificar essa realidade exige conhecimento e experiência dos professores para que possam atender às orientações legais e teóricometodológicas expressas nos documentos oficiais, considerando o desenvolvimento da criança e, assim, organizar o ensino e implementar as práticas pedagógicas de acordo com os respectivos períodos de desenvolvimento em que as crianças se encontram.

Nesse contexto, acerca das orientações legais, destacamos que se referem às finalidades das duas etapas da educação básica e as teórico-metodológicas estão relacionadas ao processo de aprendizagem e de desenvolvimento, ambas difundidas por meio de documentos oficiais elaborados e disponibilizados pelo MEC e pelo CNE.

Nessa direção, os documentos analisados significam muito mais que caminhos repletos de modificações, de avanços e de retrocessos, já que a maior preocupação é organizar, de modo unificado, o ensino das escolas e dos centros de educação infantil.

Dessa forma, compreendemos que na educação infantil as aprendizagens englobam os comportamentos, as habilidades e os conhecimentos quanto às vivências capazes de promover a aprendizagem e o desenvolvimento. Já no ensino fundamental, ocorre a consolidação dessas aprendizagens e a ampliação de suas práticas e experiências, levando em consideração seus interesses e suas perspectivas quanto ao que ainda precisam aprender.

Em consonância com Kramer (2006), entendemos que a educação infantil e o ensino fundamental, embora sejam etapas da educação básica brasileira com finalidades distintas, ambas se completam e dependem uma da outra. Ou seja, entre elas deve ocorrer continuidade, principalmente no que se refere ao processo de aprendizagem e de desenvolvimento das crianças.

Em síntese, defendemos, por meio dos apontamentos oriundos da análise dos documentos aqui mencionados, e com base nos ensinamentos da THC, a importância da transição e da articulação entre as duas primeiras etapas da educação básica. Elas necessitam de uma reorganização do ensino de modo a integrar suas práticas pedagógicas a fim de possibilitar às crianças a apropriação de novos conhecimentos e de novas formas de pensar e de agir em sociedade, tendo em vista a continuidade do seu processo de aprendizagem e de desenvolvimento, sem deixar de considerar a periodização do desenvolvimento infantil. 
SANTOS, M. M. de O.; LUCAS, M. A. O F.

Artigo recebido em: 20/08/2020

Aprovado para publicação em: 30/12/2020

\section{TRANSITION AND ARTICULATION BETWEEN EARLY CHILDHOOLD EDUCATION AND ELEMENTARY SCHOOL: OFFICIAL DOCUMENTS ANALYSIS}

ABSTRACT: This article seeks to examine some legal guidelines and theoretical-methodological guidelines published by official documents prepared by the Ministry of Education and the National Education Council, about the transition and articulation between early childhood education and elementary school. This is a bibliographic research. Based on the Historical-Cultural Theory, the theoretical framework of this research, initially we discussed the relationship between teaching, learning and development. Subsequently, we revisited the purposes of early childhood and elementary education advocated by official documents and examined the concepts of learning and development present in them. From this analysis, we discussed the transition and articulation between the two stages of schooling in question, pointing out the need for reorganization of teaching.

KEYWORDS: Transition. Articulation. Early Childhood Education. Elementary School.

TRANSICIÓN Y ARTICULACIÓN ENTRE EDUCACIÓN INFANTIL Y EDUCACIÓN PRIMARIA: ANÁLISIS DE DOCUMENTOS OFICIALES

RESUMEN: Este artículo tiene como objetivo examinar algunos lineamientos legales y teóricometodológicos que transmiten los documentos oficiales elaborados por el Ministerio de Educación y el Consejo Nacional de Educación sobre la transición y articulación entre Educación Infantil y Educación Primaria. Se trata de una investigación bibliográfica. Basada en la Teoría Histórico-Cultural, marco teórico de esta investigación, inicialmente discutimos la relación entre enseñanza, aprendizaje y desarrollo. A continuación, revisamos las finalidades de la educación infantil y de la enseñanza fundamental defendidas por documentos oficiales y examinamos los conceptos de aprendizaje y desarrollo presentes en ellos. A partir de ese análisis, discutimos la transición y articulación entre las dos etapas de escolarización en cuestión, señalando la necesidad de reorganización de la enseñanza.

PALABRAS CLAVE: Transición. Articulación. Educación Infantil. Educación Primaria.

\section{REFERÊNCIAS}

BRASIL. Constituição (1988). Constituição da República Federativa do Brasil: promulgada em 5 de outubro de 1988. São Paulo: Saraiva, 2000.

BRASIL. Lei n. 9.394, de 20 de dezembro de 1996. Estabelece as diretrizes e bases da educação nacional. Diário Oficial da União, Brasília, DF, 1996. 
BRASIL. Lei n. 10.172, de 9 de janeiro de 2001. Aprova o Plano Nacional de Educação e dá outras providências. Diário Oficial da União, Brasília, DF, 2001.

BRASIL. Lei n. 11.114, de 9 de maio de 2005. Altera os arts. 6, 30, 32 e 87 da Lei n. 9.394, de 20 de dezembro de 1996, com o objetivo de tornar obrigatório o início do ensino fundamental aos seis anos de idade. Diário Oficial da União, Brasília, DF, 2005.

BRASIL. Lei n. 11.274, de 6 de fevereiro de 2006. Altera os arts. 29, 30, 32 e 87 da Lei n. 9.394 de 20 de dezembro de 1996, dispondo sobre a duração de 9 (nove) anos para o ensino fundamental, com matrícula obrigatória a partir dos 6 (seis) anos de idade. Diário Oficial da União, Brasília, DF, 2006.

BRASIL. Resolução CNE/CEB n. 5, de 17 de dezembro de 2009. Fixa as Diretrizes Curriculares Nacionais para a Educação Infantil. Diário Oficial da União, Brasília, DF, 2009a.

BRASIL. Parecer CNE/CEB n. 20, de 11 de novembro de 2009. Revisão das Diretrizes Curriculares Nacionais para a Educação Infantil. Diário Oficial da União, Brasília, DF, 2009b.

BRASIL. Parecer CNE/CEB n. 11, de 07 de julho de 2010. Diretrizes Curriculares Nacionais para o Ensino Fundamental de 9 (nove) anos. Diário Oficial da União, Brasília, DF, 2010a.

BRASIL. Resolução CNE/CEB n. 7, de 14 de dezembro de 2010. Fixa as Diretrizes Curriculares Nacionais para o Ensino Fundamental de 9 (nove) anos. Diário Oficial da União, Brasília, DF, $2010 \mathrm{~b}$.

BRASIL. Ministério da Educação. CNE/CEB. Diretrizes Curriculares Nacionais para a Educação Básica. Brasília, $2013 a$.

BRASIL. Lei n. 12.796, de 4 de abril de 2013. Altera a Lei n. 9.394, de 20 de dezembro de 1996. Diário Oficial da União, Brasília, DF, 2013 b.

BRASIL. Ministério da Educação. Base Nacional Comum Curricular. Brasília, DF, 2017.

KRAMER, S. A política do pré-escolar no Brasil: a arte do disfarce. Rio de Janeiro: Dois Pontos, 1987.

KRAMER, S. A criança de 0 a 6 anos nas políticas educacionais o Brasil: educação infantil e/é fundamental. Educação \& Sociedade, Campinas, v. 27, n. 96, p. 797-818, out. 2006. 
SANTOS, M. M. de O.; LUCAS, M. A. O F.

LEONTIEV, A. N. Uma contribuição à teoria do desenvolvimento da psique infantil. In: VIGOTSKI, L. S.; LURIA, A. R.; LEONTIEV, A. N. (org.). Linguagem, desenvolvimento e aprendizagem. 10. ed. São Paulo: Ícone, 2006. p. 59-83.

PASQUALINI, J. C.; EIDT, N. M. Periodização do desenvolvimento infantil e ações educativas. In: PASQUALINI, J. C.; TSUHAKO, Y. N. (org.). Proposta Pedagógica para a Educação Infantil do Sistema Municipal de Ensino de Bauru/SP. Bauru: Secretaria Municipal de Educação, 2016. p. 101-148.

SFORNI, M. Ensino, aprendizagem e desenvolvimento: contribuições da teoria da atividade. In:OLIVEIRA, M. C. S. L de. et al. (org.). Psicologia dos processos de desenvolvimento humano: cultura e educação. Campinas: Alínea, 2016. p. 53-66.

VIGOTSKY, L. S. Obras escogidas II. 2. ed. Madrid: Centro de Publicaciones del M.E.C. y Visor Distribuiciones, 2001.

VIGOTSKII, L. S. Aprendizagem e desenvolvimento intelectual na idade escolar. In: VIGOTSKII, L. S.; LURIA, A. R.; LEONTIEV, A. N. (org.). Linguagem, desenvolvimento e aprendizagem. São Paulo: Ícone, 2006. p. 103-118.

Mayra Maria de Oliveira Santos: Possui graduação em Pedagogia pela Faculdade de Apucarana (2017), especialização em Educação Especial pelo Instituto Rhema de Educação e mestrado em Educação pela Universidade Estadual de Maringá (2020). É professora concursada do Ensino Fundamental I no Município de Apucarana-PR.

Orcid: https://orcid.org/0000-0002-0785-8806

E-mail: mayra-pesquisa@hotmail.com

Maria Angélica Olivo Francisco lucas: É graduada em Pedagogia pela Universidade Estadual de Maringá (1987), mestre em Educação também pela Universidade Estadual de Maringá (1999) e doutora em Educação pela Universidade de São Paulo (2009). Realizou estágio de pós-doutoramento na Faculdade de Educação da Universidade de São Paulo (FEUSP) no período 2016 a 2017. É professora associada da Universidade Estadual de Maringá onde trabalha desde 1998 e atua no Programa de Pós-Graduação em Educação (PPE) desta instituição.

Orcid: https://orcid.org/0000-0003-1568-9341

E-mail:mangelicaofl@gmail.com

Este periódico utiliza a licença Creative Commons Attribution 3.0, para periódicos de acesso aberto (Open Archives Initiative - OAI). 